\title{
Bem-estar e manejo pré-abate de suínos: Revisão
}

\section{Letícia Cassimiro Duarte Bispo ${ }^{1}$, Erin Caperuto de Almeida ${ }^{2^{*}}$, Fernando José dos Santos Dias'3 ${ }^{3}$ Karina Ludovico de Almeida Martinez Lopes ${ }^{4}$, André Luis da Silva Valente $^{5}$}

${ }^{1}$ Graduanda da Universidade Federal de Goiás, Regional Jataí, Departamento de Zootecnia. Jataí - GO, Brasil, e-mail: leticia_biispo@hotmail.com

${ }^{2}$ Professora da Universidade Federal de Goiás, Regional Jataí, Departamento de Zootecnia. Jataí - GO, Brasil, e-mail: erincaperuto@gmail.com

${ }^{3}$ Professor da Universidade Federal de Goiás, Regional Jataí, Departamento de Zootecnia. Jataí - GO, Brasil, e-mail: fjsdias@yahoo.com.br

${ }^{4}$ Professora da Universidade Federal de Goiás, Regional Jataí, Departamento de Zootecnia. Jataí - GO, Brasil, e-mail: karinaludovico.ufg@gmail.com

${ }^{5}$ Professor da Universidade Federal de Goiás, Regional Jataí, Departamento de Zootecnia. Jataí - GO, Brasil, e-mail: valente.unesp@gmail.com

*Autor para correspondência

\begin{abstract}
RESUMO. Objetiva-se com essa revisão apresentar formas adequadas de realizar o manejo pré-abate dos suínos, incluindo todo o manejo envolvido desde a propriedade, como coleta, carregamento e transporte, até o abate no frigorífico. Sabe-se que o manejo pré-abate é de suma importância na cadeia produtiva da suinocultura, visto que esta etapa tem influência direta na qualidade final da carne. Além disso, os consumidores vêm exigindo produtos de melhor qualidade e que não prejudiquem o meio ambiente, fazendo com que os produtores invistam em métodos que priorizem o bem-estar dos animais, mantendo sua saúde física e psicológica.
\end{abstract}

Palavras chave: Abate humanitário, jejum, transporte

\section{Welfare and pre-slaughter management of pigs: a review}

\begin{abstract}
Aim with this review come up with correct forms of handling pigs on pre slaughter time, included all the managements on the property, collect, shipment and transport until the slaughter moment. The pre-slaughter management is very important on the swine chain productive, since this affect directly the meat quality. Furthermore, consumers are demanding for higher quality products and which not damage the environment. By this sense, farmers have to maintain better animal welfare, keeping the psychological and physical of the animals.
\end{abstract}

Keywords: Fasting, humanitarian slaughter, transport

\section{Introdução}

O Brasil é um grande produtor e exportador de carne suína (FAPRI, 2015), o que torna fundamental que se tenham investimentos em diversas áreas, como na genética, sanidade, nutrição e manejo, promovendo melhorias na qualidade final da carne e na produtividade animal. Isto traz benefícios tanto para o produtor quanto para o abatedouro, resultando em redução de gastos com rações, diminuindo mortalidade no transporte da granja até $\mathrm{o}$ frigorífico e consequentemente obtendo maior aproveitamento da carcaça dos animais.

Adicionalmente, os consumidores estão se conscientizando do sentimento dos animais e passam a ter uma preocupação com o bem-estar animal, exigindo alimentos oriundos de sistema de produção onde o animal é respeitado durante toda a cadeia produtiva, e que também reduzam à agressão ao meio ambiente (Molento, 2005). Sendo assim, é necessário adequar as práticas de manejo em diversas fases da produção de suínos, 
principalmente no pré-abate e no abate de forma a atender este mercado.

Os suínos passam por diversas práticas de manuseio desde o momento do embarque na granja até a insensibilização final no momento do abate. Dentre essas práticas, está a transferência da baia que é um ambiente familiar para o interior do caminhão, com animais de diferentes lotes, e as vezes com superlotação, existindo interação com humanos e intensa atividade física, podendo causar estresse e dificuldade no manejo. Se estas etapas forem feitas em más condições, pode ocorrer hematomas, afetando as carcaças e a qualidade da carne e até levar a perdas por mortalidade (Faucitano, 2000).

Portanto, as condições de manejo pré-abate são de grande importância e é o foco desta revisão bibliográfica, visto que melhorias nesta etapa da cadeia produtiva dos animais ocasionam um aumento do bem-estar dos suínos e consequente redução de perdas econômicas, com uma melhor qualidade da carne para os consumidores.

\section{Bem-estar de suínos}

O conceito de bem-estar da Farm Animal Welfare Council - FAWC (2009) considera que para as condições de bem-estar do animal a cadeia produtiva deve respeitar cinco critérios, conhecido como as cinco liberdades. O animal deve estar livre de fome e de sede, tendo acesso a uma dieta saudável e adequada às suas condições fisiológicas e água fresca de qualidade; estar livre de desconforto, com o fornecimento de um ambiente apropriado, com espaço suficiente para movimentação e que inclua um abrigo com zona de descanso confortável; estar livre de dor, ferimentos e doença, com prevenção de doenças, diagnóstico rápido e tratamentos adequados, ser livre para expressar comportamento normal, instalações adequadas e socialização com animais da mesma espécie e livre de stress, medo e ansiedade, assegurando condições que evitem sofrimento mental, como angústias e frustrações.

Segundo a OIE (2016), o bem-estar animal pode ser definido como o modo em que o animal lida com as condições em que o cerca. Para o animal estar em bem-estar ele deve estar saudável, seguro, confortável, em bom estado nutricional, ser capaz de expressar comportamentos apropriados e não estar passando por situações desagradáveis que envolvam dor, medo e aflição. Engloba a prevenção e tratamento correto de doenças, manejo correto, nutrição e abate humanitário.

No Brasil a legislação de bem-estar animal teve início com o Decreto $\mathrm{n}^{\circ} 24.645$ de julho de 1934, que estabelece medidas de proteção animal. A Constituição Federal de 1988, no seu artigo $\mathrm{n}^{\mathrm{o}} 225$, dota o poder público de competência para proteger a fauna e a flora, vedando práticas que submetam os animais a crueldade. Nesta lógica a Comissão Técnica Permanente de Bem-Estar Animal do Mapa, instituída através da Portaria $\mathrm{n}^{\circ} 185$ de março de 2008 (atualizada pela Portaria $\mathrm{n}^{\circ} 524$ de 2011), tem o objetivo de coordenar as diversas ações de bem-estar animal do Ministério e fomentar a adoção das boas práticas para o bem-estar animal pelos produtores rurais, sempre embasadas na legislação vigente e no conhecimento técnicocientífico disponível.

O bem-estar animal e a busca por uma maior segurança alimentar, faz parte, cada vez mais, da consciência pública dos países desenvolvidos (Silva et al., 2011). Atualmente no Brasil, os produtores vêm de forma gradativa, buscando por melhorias nas técnicas de produção e abate de animais, motivados pelo modelo europeu e pelas legislações da União Europeia, visto que é de grande interesse dos brasileiros ampliar as fronteiras comerciais de exportação de carnes. No entanto, para ser aceito pelos consumidores europeus, é necessário que o produtor brasileiro se adeque as práticas de manejo de acordo com as exigências destes países (aj, 2000).

Além de abertura de novos mercados, a adequação dos métodos de bem-estar na produção animal e no manejo pré-abate contribuem para o aumento de produtividade. Desta forma, é preciso seguir à risca os princípios do bem-estar em todas as fases da cadeia produtiva, principalmente nas operações de transporte, onde se verificam elevados índices de perdas pelo estresse sofrido pelos animais (Santos et al., 2013).

\section{Preparo de suínos terminados para o transporte}

No momento da separação dos lotes dos suínos que serão destinados ao abate, é importante observar se todos os animais estão saudáveis o suficiente para que possam ser embarcados e transportados até o abatedouro. Caso seja verificado que há animais enfermos, debilitados ou com alguma incapacidade de se 
locomover, o responsável técnico da granja deve ser acionado para que sejam feitas as medidas e tratamentos corretos, visto que é uma carne que será direcionada ao consumo humano. Em situações onde há necessidade de sacrifício do animal, este deve ser feito utilizando métodos humanitários, por um profissional capacitado e treinado.

Suínos cansados, ofegantes e com dificuldade de locomoção devem permanecer descansando nas baias com bebedouro próximo e serem conduzidos por último até o caminhão, de modo que sejam os primeiros a desembarcar no frigorífico, tendo uma menor movimentação (Dalla Costa et al., 2007).

O jejum pré-abate é uma medida fundamental no ciclo de produção dos suínos, ele tem início na granja e termina no frigorífico. Quando se inicia o jejum, o fornecimento de alimentos sólidos é suspenso, mas a água deve ser fornecida à vontade (Dalla Costa et al., 2009).

Segundo Dalla Costa et al. (2008), a prática do jejum tem grande relevância para os produtores e abatedouros pois influencia no bemestar dos animais durante o transporte, reduzindo a taxa de mortalidade dos suínos, diminui a quantidade de animais que vomitam ao serem transportados, tem uma maior segurança alimentar pois previne a liberação e proliferação de bactérias pelas fezes, possibilita maior facilidade no processo de evisceração e melhor padronização e rendimento de carcaças, além de reduzir a quantidade de dejetos.

$\mathrm{O}$ tempo recomendado para o jejum dos animais é de 10 a 24 horas; porém existe variação de acordo com o país e com o perfil genético dos suínos (Dalla Costa et al., 2010)). Suínos que passam por um jejum de 24 horas ou mais, podem sofrer perdas qualitativas e quantitativas da carne, podendo perder até $5 \%$ de seu peso corporal, a uma taxa de $0,2 \%$ por hora, valor que pode variar quanto mais pesado forem os animais. Por exemplo, indivíduos com $71 \mathrm{~kg}$ de peso submetidos a jejum de 48 horas podem perder até $5 \mathrm{~kg}$ do peso $(0,11 \mathrm{~kg} / \mathrm{hora})$ (Dalla Costa et al., 2008).

Beattie et al. (2002) notaram que jejum de 12 horas antes do abate levou a uma economia de $1,5 \mathrm{~kg}$ de ração e não ocorreram perdas na qualidade de carcaça, o que foi benéfico para os criadores. Entretanto, jejum de até 20 horas ocasionou maior perda de peso nas carcaças, na média de $1 \mathrm{~kg}$.

Com o tempo excessivo de jejum dos suínos, desde a granja até o momento de abate, os cortes podem apresentar carne DFD (escura, dura e seca), este defeito na qualidade da carne acomete animais submetidos a estresse de longa duração (crônico). E pode ter o aparecimento da carne PSE (pálida, mole e exsudativa) que normalmente está associada ao estresse intenso (agudo), ocasionado pelo manejo inadequada, do início até o momento próximo do abate. Isto causa sérios prejuízos econômicos, pois a carcaça pode ser condenada, por não estar apta para o consumo in natura (Ricci \& Dalla Costa, 2015).

Gispert et al. (2000) observaram maior incidência de carnes PSE, no verão, quando o período de jejum na granja foi maior que 12 horas e densidade no caminhão menor que $0,40 \mathrm{~m}^{2} / 100 \mathrm{~kg}$, com a duração do transporte maior que duas horas. Porém, no inverno, houve maior incidência de carnes DFD, com densidade no caminhão superior a $0,40 \mathrm{~m}^{2} / 100 \mathrm{~kg}$, duração de transporte maior que duas horas e período de descanso maior que nove horas.

De acordo com Murray (2000) retirar a ração 20 horas antes do abate, irá reduzir o peso do trato gastrointestinal em um a dois quilos a mais do que se retirar com cinco horas. $\mathrm{O}$ que pode significar $10.000 \mathrm{~kg}$ de dejetos de um abatedouro que processa cerca de 8.000 suínos por dia. Segundo Dalla Costa et al. (2008), essa suspensão do fornecimento do alimento pode levar os suínos a ingerir restos de rações que ficam no chão, por isso recomenda-se a limpeza das baias para evitar uma maior contaminação das carcaças, também deve ser feita a retirada das sobras dos comedouros. Essa situação gera estresse nos suínos e com isso aumenta a quantidade de brigas, sendo assim, para evitar contusões e lesões que prejudiquem a qualidade final da carne, podem ser oferecidos objetos que distraiam a atenção dos animais, como cordas, correntes e garrafas penduradas.

Alguns fatores importantes devem ser observados e corrigidos na granja para promover uma melhor condução dos animais até $o$ embarcadouro, como: a falta de portas nas unidades de terminação; iluminação inadequada nos galpões e corredores; falta de laterais que permitam aos animais olharem para fora; mudanças no ângulo que façam os animais perderem o contato visual ou corporal; piso 
demasiadamente liso ou feito de vários materiais (Dalla Costa et al., 2006).

A retirada dos suínos da baia deve ser realizada de modo tranquilo e eficiente, pois é uma mudança brusca de ambiente para os animais. $\mathrm{O}$ mais recomendado é retirar primeiro os suínos das baias mais próximas do local do embarque, evitando o estresse dos outros animais que perceberão uma movimentação diferente no local. Devido ao suíno ser um animal curioso, recomenda-se conduzir de dois a três animais por vez com o objetivo de reduzir as paradas durante a passagem no corredor, evitando estresse (Dalla Costa et al., 2010).

Lewis \& Berry (2006) avaliando o efeito do tamanho do grupo constataram que grupos pequenos de quatro a cinco animais levados à rampa de embarque são mais fáceis de manejar, o que resultou em diminuição dos batimentos cardíacos, se comparado a grandes grupos, de oito a dez animais. Todavia, provoca um aumento no tempo necessário para concluir o embarque de todos os suínos.

Faucitano (2000) afirma que o momento de interação homem-animal é o estágio mais crítico antes do embarque, pois ao mudar de ambiente são induzidos a uma atividade física moderada nos corredores e rampas o que pode deixar os animais nervosos, dificultando o manejo. Os animais não devem sofrer agressões, mas este processo deve ser feito da forma mais ágil possível. Existe um método que possibilita encorajar os animais a mover-se para frente, que é empurrando o grupo por trás com painéis. Esta técnica reduz o tempo para chegarem até o caminhão, não ocorrendo estresse. É proibido o uso de varas e objetos contundentes para a condução dos animais, pois prejudica o bem-estar animal, é doloroso, o animal pode sentir pânico e causam hematomas, prejudicando a carcaça.

No experimento de Correa et al. (2010), os suínos que foram conduzidos com choque elétrico apresentaram maior quantidade de lesões de pele e maior número de animais cansados, com concentrações elevadas de lactato no plasma e presença de hemorragia nos músculos.

Objetos como chocalhos, podem ser utilizados para auxiliar na locomoção dos suínos, que por fazerem barulhos, estimulam os animais a continuarem se movimentando. O contato leve com as mãos na região do flanco do animal também pode ser utilizado, pois estimula o movimento pelo contato físico (Dalla Costa et al., 2008). Os tratadores devem ser responsáveis, pacientes e não utilizar da força para estimular os animais a caminharem. Algumas falhas de manejo causadas pelo funcionário podem ser resultado do trabalho sob pressão ou por falta de conhecimento e experiência prática, por isso é indicado fazer um treinamento de funcionários para se tornarem aptos, visando diminuir a dor e estresse desnecessário aos animais, além de diminuir prejuízos por lesões. É indicado antes da saída da granja emitir um relatório com visto do produtor com a quantidade de animais já lesionados antes do embarque para se ter um controle das atitudes dos tratadores, incluindo também o transportador (Miranda-de la Lama et al., 2010).

As rampas de embarque devem ter inclinação suave e não superar um ângulo de $20^{\circ}$, pois os suínos apresentam dificuldades em angulações maiores, ocorrendo maior incidência de hemorragias no pernil dos suínos (Dalla Costa et al., 2009). As rampas devem permitir uma subida fácil para os suínos, por isso é essencial que tenha aproximadamente 1 metro de largura e que as paredes laterais tenham por volta de 0,80 metros, impedindo quedas e que os animais visualizem e se distraiam com o ambiente externo (Ricci \& Dalla Costa, 2015).

A granja deve dispor de embarcadouro que permita a passagem de dois animais ao mesmo tempo, possibilitando maior facilidade no manejo, com constante contato visual. É necessário verificar se no embarcadouro há presença de materiais que possam causar lesões, como pregos, buracos, pontas salientes, dentre outras e observar se há objetos estranhos por perto que farão os suínos recuarem.

$\mathrm{O}$ piso preferencialmente deve ser antiderrapante, porém pode ser feito o uso de uma boa quantidade de serragem ou maravalha, que formará uma camada grossa sobre a rampa e com isso a umidade proveniente da urina e das fezes vai ser reduzida, evitando dessa forma escorregões e quedas durante o embarque. Este material de cobertura pode ser reposto sempre que for necessário, fazendo o manejo com calma, evitando o sofrimento para os animais (Dalla Costa et al., 2009).

Dalla Costa et al. (2009) recomenda que após o embarque ter sido finalizado, os animais sejam molhados com o auxílio de aspersores de água localizados na carroceria do caminhão. Como os 
suínos foram submetidos a atividade física nos corredores do galpão de terminação, este procedimento ajudará a reduzir a temperatura corporal e o estresse por estar em um novo ambiente. O período ideal é de 30 minutos contínuos de aspersão após o embarque, para que os animais fiquem menos agitados.

É dever do motorista do caminhão verificar se os aspersores estão em perfeitas condições bem como qualquer outro tipo de problema antes do embarque, que possa causar algum tipo de dano aos animais (Miranda-de la Lama et al., 2014).

\section{Cuidados no transporte de suínos para o abate}

Segundo Garcia \& McGlone (2015) o transporte adequado dos animais é de suma importância, pois a falta de bem-estar nessa etapa pode causar grandes prejuízos para a indústria de carne suína. As perdas no transporte envolvem muitos fatores, desde atitude dos funcionários, comportamento animal, instalações de abate, fatores ambientais, até fatores como a genética, estado de saúde, peso corporal, musculosidade da carcaça, dentre outros. É relevante que as operações para o transporte dos animais sejam bem programadas, considerando o bem-estar animal, as boas práticas de manejo e o conforto térmico, visto que descuidos neste processo ocasionam ansiedade, medo, aumento dos batimentos cardíacos, dentre outros sintomas (Machado et al., 2014). Animais criados em sistemas de produção onde existem práticas inadequadas de manejo apresentam maiores quantidades de lesões nas carcaças, como lacerações, eritemas e hematomas, causando depreciações nas mesmas (Esteves et al., 2014). No momento do transporte acontecem situações que causam aumento do estresse dos suínos pois os animais são expostos a atividade física para o embarque e desembarque, ocorrem barulhos, vibrações, mudanças repentinas de velocidade do caminhão e variações na temperatura ambiental. Todos estes fatores contribuem para a pior qualidade da carne e menor rendimento de carcaça (Ludtke et al., 2012).

Caso for embarcar um maior número de animais, onde seja necessário dois ou mais caminhões, é fundamental que a propriedade tenha um planejamento do tempo médio de embarque e horário de chegada dos veículos, com a finalidade de evitar que o local de manobra fique interditado e que os motoristas tenham que permanecer esperando por mais tempo. O tempo médio de embarque dos animais para um veículo que comporta 100 suínos deve ser entre 25 e 30 minutos.

Tanto a falta de espaço, quanto o excesso, ocasionam aumento no número de fraturas, lesões de pele e mortes no transporte, por isso deve-se estar sempre atento à densidade utilizada nos caminhões. A Legislação da União Europeia (95/29/EC) especifica a densidade de $0,425 \mathrm{~m}^{2}$ por suíno de $100 \mathrm{~kg}$ de peso vivo, ou $235 \mathrm{~kg} / \mathrm{m}^{2}$ que deve ser calculada segundo o tipo de caminhão e tamanho do lote que ocupará cada compartimento da carroceria (Dalla Costa et al., 2007).

Costa et al. (2002) observaram que na densidade de $0,35 \mathrm{~m}^{2} / 100 \mathrm{~kg}$, os suínos apresentaram irritação e tentavam empurrar uns aos outros com a cabeça e, ao final do trajeto de 45 minutos somente $20 \%$ dos animais encontravam-se deitados e $40 \%$ sentados. Já com densidade de $0,39 \mathrm{~m}^{2} / 100 \mathrm{~kg}$, os animais tiveram atitude de explorar, normalmente nos primeiros 30 minutos iniciais da viagem. Ao final do trajeto que durou quase uma hora, $57 \%$ dos animais estavam deitados e $29 \%$ sentados, apresentando uma melhor adaptação. Com densidades de 0,42 e $0,50 \mathrm{~m}^{2} / 100 \mathrm{~kg}$, os animais mudavam de posição a todo o momento e, nesta última, mostravam maior dificuldade de permanecer em equilíbrio durante o deslocamento, sendo que os níveis de creatinaquinase, enzima liberada sempre que o animal passa por grande estresse físico, foram inferiores aos das densidades de 0,35 e $0,39 \mathrm{~m}^{2} / 100 \mathrm{~kg}$. Segundo Dalla Costa et al. (2007) alta densidade populacional de suínos durante o transporte faz com que os animais se sintam incomodados por não conseguirem deitar todos ao mesmo tempo, o que resulta em um suíno sentando sobre o outro, causando dificuldade na respiração dos mesmos (dispneia). Densidades altas também causam agitações e pânico quando a temperatura é maior que $15^{\circ} \mathrm{C}$, porém quando a temperatura do ar é menor que $5^{\circ} \mathrm{C}$ os animais permanecem tranquilos durante $\mathrm{o}$ trajeto, pois pelo contato físico evitam a perda de calor. Em contrapartida, densidades baixas possibilitam maior conforto, mas também não são recomendadas, pois permitem a movimentação dos suínos devido ao maior espaço e isto faz com que eles se machuquem batendo nas paredes dos veículos ou se chocando uns com os outros. Além dos danos observados nos animais, o custo de transporte aumenta, tornando-se inviável em termos produtivos (Israel 
et al., 2010). Guàrdia et al. (2005) observaram um aumento na incidência de lesões de pele e agressões quando foram utilizados espaços maiores que $0,35 \mathrm{~m}^{2}$ por suínos de $100 \mathrm{~kg}$.

Os caminhões utilizados para realizar o transporte dos suínos, podem ser do tipo gaiola, com piso móvel ou fixo e, também, podem ser simples, dupla ou tripla. A gaiola e o piso, normalmente, são de metal ou de madeira, sendo internamente dividida em compartimentos, onde os suínos serão dispostos em grupos (Santos et al., 2013). O modelo do veículo de transporte pode prejudicar o bem-estar dos suínos. Países como a Inglaterra têm substituído veículos com carrocerias normais por veículos com carrocerias de piso móvel, o que facilita o embarque e desembarque dos animais e diminui intervenções agressivas no manejo (Ludtke et al., 2012). Schwartzkopf-Genswein et al. (2012) afirmam que a disposição dos suínos no veículo de transporte, no piso e nos andares, reflete na produção e na qualidade final da carne, gerando assim impactos que levam às perdas. É fundamental observar o tipo de veículo, de piso, a distribuição dos suínos na carroceria e as condições de ventilação no período do transporte para verificar se esta etapa será eficiente e com reduzidos impactos nos animais. São recomendados veículos com carrocerias compartimentadas pois oferecem maior conforto para os animais, o caminhão deve ter no máximo dois pisos e possuir carroceria metálica. É importante observar que cada tipo de veículo afetará de uma maneira diferente no bem-estar do animal. Kephart et al. (2010) fizeram observações durante o transporte até o frigorífico em 41.744 suínos destinados ao abate, em diferentes tipos de caminhões, e relataram que a quantidade de animais com dificuldade respiratória foi maior em veículos mais compartimentados, pois os suínos precisavam caminhar por diversas rampas dentro do veículo com inclinação de $20^{\circ}$, e com isso ficavam ofegantes após o transporte em comparação aos outros tipos de veículos com plataformas hidráulicas. Dalla Costa et al. (2007) também recomendam caminhões de dois andares, considerando-os como veículos ideias para o transporte de suínos, sendo que devem possuir pisos revestidos com borracha leve. Segundo Dalla Costa et al. (2006), os animais que foram conduzidos em carroceria simples apresentaram valores significativamente maiores de lesões de pele no desembarque e após 24 horas de abate, quando comparado com os suínos conduzidos em carroceria dupla. Dalla Costa et al. (2010) afirmam que a maioria dos animais que são transportados no piso inferior do veículo sofre mais escoriações nas paletas, nas regiões do tórax e do abdômen, pois estão mais perto do asfalto ou do solo comum e recebem mais vibrações e solavancos, tornando mais difícil para os suínos se manterem em pé, durante o transporte.

Os modelos de veículos com três pisos não são os mais recomendados por possuírem rampas internas entre os andares, que dificulta o manejo no desembarque dos animais além de possuírem menor espaço entre os pisos, o que reduz a ventilação e o acesso dos funcionários que auxiliam na condução dos animais. Já os veículos com piso móvel, não possuem os problemas com relação à maiores angulações das rampas, tanto internas do caminhão, quanto do embarcadouro nas granjas e do desembarcadouro nos frigoríficos, facilitando o manejo dos suínos, sendo possível que os tratadores acomodem os animais nos compartimentos do veículo com o auxílio de painéis (ABCS, 2016).

A estrutura dos veículos, visando promover o conforto térmico, também é muito importante, pois os suínos sofrem muito com as variações climáticas, principalmente com o calor, por possuírem pequeno número de glândulas sudoríparas funcionais, dificultando a regulação da temperatura corporal e a troca de calor. Por isso o esforço físico no manejo pré-abate causa estresse térmico, tornando necessário o uso de sistemas de aspersão de água acoplado à carroceria, ajudando a minimizar esses efeitos. É indicado que a temperatura interna da carroceria não seja maior que $18^{\circ} \mathrm{C}$.

O transporte deve ser feito nos horários mais frescos do dia, preferencialmente nas primeiras horas da manhã ou durante a noite, sempre de forma cautelosa. Deve-se evitar transportar os animais para longas distâncias, assim como misturá-los em diferentes lotes e exposição excessiva ao sol, chuva ou ventos, utilizando veículo coberto. No entanto, o tempo de transporte é mais importante que a distância percorrida, visto que existem fatores que afetam o tempo, como a duração do embarque nas várias granjas, tráfego lento, engarrafamento, dentre outros. Estes fatores podem deixar os animais ainda mais agitados, aumentado a fadiga que ocorre nesse período. 
De acordo com o Department for Environment Food and Rural Affairs (DEFRA) o tempo máximo para transporte de suínos é de 24 horas, incluindo os intervalos para fornecimento de água, comida ou descanso.

A Empresa Brasileira de Pesquisa Agropecuária (EMBRAPA) sugere que sejam adotados cuidados especiais com os animais nas viagens em que o tempo seja superior a três horas, fazendo uma escolha criteriosa da qualidade do trajeto. Distâncias muito curtas podem não permitir um relaxamento muscular no suíno, aumentando o estresse e consequentemente afetando a qualidade da carne. Por outro lado, distâncias longas também podem aumentar o estresse e prejudicar a carne do animal, devido ao maior tempo de jejum e as maiores movimentações no veículo.

Yu et al. (2009) comparando a qualidade da carne dos suínos transportados após uma, duas e quatro horas, observaram que a qualidade da carne suína foi inferior após duas horas, apresentando maior probabilidade de carne PSE, em comparação a uma e quatro horas de transporte. Contrariando estes resultados Dalla Costa et al. (2007) recomendam quando possível realizar o transporte em curtas distâncias, pois acima de 4 horas de viagem, os animais entram em nível elevado de estresse. Apesar do transporte de maior duração ser mais associado com a preocupação em relação ao bem-estar animal do que as viagens mais curtas, não é de fato a viagem que provoca o desconforto em si, mas sim as condições climáticas (temperaturas extremas), a privação de água e comida e pouco descanso. Dessa forma, é importante que os animais estejam saudáveis e que as condições de transporte sejam adequadas para longos trajetos, evitando assim que o bem-estar dos suínos seja afetado (Nielsen et al., 2011).

Outro ponto a se considerar, e que influencia nos prejuízos durante o transporte é o comportamento do motorista e como ele conduz o caminhão. O ideal é que seja feito por motoristas treinados, porém isso nem sempre acontece devido a terceirização, que dificulta o melhor acompanhamento do serviço. Alguns motoristas, devido ao horário de entrega e a pressão de cumprir o tempo de viagem, deixam de ter cuidados básicos, como desviar de buracos na rodovia, evitar frear ou acelerar de forma brusca e utilizar aspersores em dias com altas temperaturas. Estes fatores, juntamente com o uso indevido de bastão elétrico e falta de treinamento, leva a um maior número de lesões nos animais (Santos et al., 2013) Para o animal ter um descanso adequado durante o trajeto é necessário que o condutor seja prudente na forma de acelerar, na frenagem e no modo de fazer as curvas, pois estes influenciam na capacidade dos animais manterem sua postura. Por exemplo, aumento na aceleração, provocará nervosismo nos animais que tentarão se manter de pé e isso novamente acabará resultando em perdas (Miranda-de la Lama et al., 2014). Contratar um motorista treinado e que preze pelo bem-estar animal pode ser um ponto positivo, em razão de afetar diretamente no lucro da produção e na qualidade final do produto (Miranda-de la Lama et al., 2010).

Ao chegarem ao frigorífico, o desembarque deve seguir o mesmo manejo adotado no embarque, sendo feito de forma tranquila, visto que os suínos possuem uma dificuldade de descer rampas principalmente com inclinações superiores a $15-20^{\circ}$, utilizando painéis de manejo para auxiliar na condução e evitando assim o uso de bastões de choque ou equipamentos que forcem os animais a descer do veículo, o que pode acarretar em ferimentos (Dalla Costa et al., 2009).

Apesar de atualmente ser recomendado rampas abaixo de $20^{\circ}$, os regulamentos não dão enfoque ao piso com materiais antiderrapantes, o que resulta em perdas também por deslizamentos e quedas dos animais no momento da descida do veículo. Os autores observaram que quanto maior for a declividade da rampa maior será o tempo para finalizar o desembarque e maior será o aumento da frequência cardíaca (Garcia \& McGlone, 2015).

Caso exista um grande número de veículos para desembarcar os animais, é necessário que alguns dos caminhões permaneçam em um local de espera, protegido de intempéries (Baptista et al., 2011). É de alta relevância que as instalações da plataforma de recepção dos suínos sejam adequadas, uma vez que exposição ao vento, chuva ou sol forte, pela falta de cobertura na plataforma do desembarque, ocasiona atrasos na descida dos animais do veículo, pois com isso a condução se torna mais difícil. O tempo de espera de desembarque pode variar, podendo ser em minutos ou se estender até por três ou quatro horas (Dalla Costa et al., 2010). 
Segundo Dalla Costa et al. (2010) é necessário um período de descanso adequado para que os animais reestabeleçam seu equilíbrio homeostático e se recuperem do estresse que passaram durante todos os procedimentos anteriormente citados. Ricci \& Dalla Costa (2015) afirmam que o descanso juntamente com o jejum e dieta hídrica visam reduzir o conteúdo gástrico, facilitando a evisceração da carcaça e o reestabelecimento das reservas de glicogênio muscular, que serão fundamentais para o correto estabelecimento do rigor mortis. Owen et al. (2000) afirmam que suínos que não passam por um período de descanso apresentam maiores porcentagens de carcaças com problema de carne PSE, comparando aos que descansam por uma a duas horas. Suínos que são submetidos a pequenos períodos de descanso (menos de duas horas) no frigorífico, tendem a apresentar valores baixos de $\mathrm{pH}$ dos músculos e animais com longos períodos de descanso tendem apresentar valores elevados de $\mathrm{pH}$ dos músculos. Essa variação do $\mathrm{pH}$ está relacionada com as reservas de glicogênio e a presença de ácido láctico (Owen et al., 2000). Carcaças com carne do tipo PSE desenvolvem-se em função da rápida redução do $\mathrm{pH}$ e isso consequentemente gera rápida acumulação de ácido lático pelo intenso consumo de glicogênio. $\mathrm{O}$ pH 24 horas após o abate atinge valores iguais ou inferiores a 5,5. Menor capacidade de retenção de água, cor pálida e textura flácida, é o que torna a carne indesejável para o consumo. Por outro lado, as carnes DFD são resultado do rápido esgotamento das reservas de glicogênio, que mantém os valores do $\mathrm{pH}$ superiores a 6,0. Este valor elevado do $\mathrm{pH}$, acompanhado da cor escura e da retenção de água superior ao normal confere à carne DFD, um aspecto pouco atrativo aos consumidores. Além disso, carnes DFD, por apresentarem estas características, possuem vida de prateleira muito curta pelo alto teor de umidade, o que favorece a multiplicação de bactérias que causam deterioração. $\mathrm{O}$ ideal é que o $\mathrm{pH}$ final da carne tenha uma queda de 7,2-7,0 para 5,3-5,8 em seis a oito horas post mortem.

O período de descanso adequado no frigorífico é essencial para o bem-estar dos animais, permite que eles se recuperem do estresse físico e emocional que sofreram durante o tempo no transporte. Geralmente um período de uma a três horas nas baias é suficiente para essa recuperação, porém esse prazo pode variar conforme a logística do estabelecimento e de acordo com o grau do estresse que os animais foram submetidos em todo o manejo pré-abate (Santiago et al., 2012). Köhler \& Freitas (2005) realizaram um experimento, com o objetivo de estudar o efeito de dois tempos de descanso no frigorífico, com mínimo de três horas e máximo de nove horas, avaliando as características de $\mathrm{pH}$ e capacidade de retenção de água da carne suína. Os autores não observaram diferenças estatísticas significativas na qualidade da carne, e com isso recomendam a redução do tempo de descanso dos animais nas baias. Confirmando este resultado, Dalla Costa et al. (2006) avaliaram o tempo de descanso variando de três a nove horas para verificar o efeito do tempo sobre a perda de peso corporal e concluíram que a variação das horas neste período não afeta as características do estômago e nem a perda de peso dos animais.

Suínos que apresentam sintomas de dor, ferimentos, caudofagia, hérnias, problemas locomotores, dentre outros, precisam ser colocados em baias separadas onde sejam monitorados adequadamente. Caso seja necessário misturar animais de diferentes lotes, deve-se evitar que descansem por um período muito longo, em razão de ocorrer brigas pelo estabelecimento de uma nova hierarquia social. É indicado separar os machos inteiros para reduzir a agitação e as disputas nos grupos (Ricci \& Dalla Costa, 2015).

Dalla Costa et al. (2006) afirmam que condições inadequadas no período de descanso podem causar mais estresse para os animais ao invés de trazer benefícios, por isso o ideal é evitar ambientes com excesso de barulho de pessoas, calor e ruídos de máquinas ou mangueiras de água, também deve-se evitar altas densidades, que favorecem o aumento no número de agressões entre os grupos. Os suínos devem permanecer em jejum de sólidos durante o descanso, recebendo apenas água limpa, mas se mantidos por mais de 24 horas, devem receber alimentação em quantidade e intervalos apropriados. De acordo com Faucitano (2000) no período de descanso pode ocorrer interferências de fatores climáticos, mas que poderão ser resolvidos. A zona de conforto térmico para os suínos situa-se entre 15 a $18^{\circ} \mathrm{C}$ e 59 a $65 \%$ de umidade relativa do ar. Em temperaturas maiores que estas os animais têm dificuldade para perder calor, e deitam-se, o que promove a elevação da frequência respiratória. $\mathrm{O}$ recomendado nestes casos é obter o auxílio de um mecanismo de ventilação para diminuir a temperatura do ar. $\mathrm{O}$ 
uso de água fria através de aspersão com temperatura de 9 a $10^{\circ} \mathrm{C}$ é possível refrescar os animais, além de auxiliar na pré-lavagem do couro. Este procedimento diminui o esforço cardiovascular causado pelo calor. Reduzindo a temperatura corporal, resultando em menor perda de água na carcaça. A aspersão de água nos suínos também influenciará na melhor eficiência do atordoamento elétrico e irá assegurar uma melhor sangria devido à vasoconstrição periférica, processo que também está relacionado com a manutenção e a regulação da temperatura corporal.

\section{Abate humanitário de suínos em terminação}

$\mathrm{O}$ abate humanitário de animais para consumo humano, segundo a Instrução Normativa $n^{\circ} 3$, de 17 de janeiro de 2000, do Ministério da Agricultura, Pecuária e Abastecimento é definido como "o conjunto de diretrizes técnicas e científicas que garantem o bem-estar dos animais desde a recepção até a operação de sangria".

A redução da mortalidade, a fidelização de mercados exigentes, melhores condições para animais e funcionários, redução das perdas por hematomas, contusões, fraturas e menor quantidade de perdas por defeitos na coloração e vida útil da carne são alguns dos benefícios do abate humanitário (Ludtke et al., 2012).

Os animais devem ser conduzidos para o local de insensibilização em fila única, entretanto os animais podem parar, interrompendo a organização da fila. Nesse momento é comum os funcionários utilizarem varas com ou sem choque. Por isso aglomerações com um número grande de suínos são indesejáveis, sendo recomendado movimentar um grupo pequeno, com cerca de 15 animais, por vez (Faucitano, 2000), 2000). Recomenda-se que seja realizado banho de aspersão por no mínimo três minutos, com uma pressão mínima de água de 1,5 atmosferas, para que os suínos sejam profusamente lavados.

Os métodos de insensibilização permitidos para a utilização em suínos são a insensibilização elétrica (eletronarcose ou eletrocussão) e a exposição à atmosfera controlada. $\mathrm{O}$ atordoamento ou a insensibilização pode ser relatado como a primeira operação de abate propriamente dita. É o procedimento feito no animal que visa propiciar, de forma rápida, um estado de insensibilidade que mantenha as funções vitais dos animais até a sangria. A insensibilização por eletronarcose deve-se usar alta voltagem $(350 \mathrm{~V}-750 \mathrm{~V})$ e baixa amperagem (0,5 A - 2 A). A eletrocussão é semelhante à eletronarcose, porém ao invés de dois, são três eletrodos, o terceiro é posicionado imediatamente atrás da paleta esquerda e o mais perto possível da região ventral. Neste último ponto de contato deve-se utilizar baixa frequência $(50 / 60 \mathrm{~Hz})$, o que ocasionará uma fibrilação ventricular e parada cardíaca. $\mathrm{O}$ processo de insensibilização elétrica deve ser eficaz, de modo a garantir que o animal realmente esteja insensibilizado no momento do abate, assegurando uma morte sem dor ou agonia. A ausência de vocalização e de tremores são sinais de que a insensibilização foi eficiente. A insensibilização elétrica por eletronarcose é a mais utilizada e para ser efetiva deve ser avaliada pela posição correta dos eletrodos e pela vocalização dos animais em razão do contato com os eletrodos energizados. Na prática a agitação e inquietação do animal pode causar o posicionamento inadequado dos eletrodos, no entanto o posicionamento correto é a sua colocação na região das têmporas e abaixo da base da orelha, com corrente suficiente para que o animal fique inconsciente no mesmo instante. É recomendado que a corrente elétrica para suínos de terminação seja no mínimo de 1,3 Amperes. Se os eletrodos estiverem posicionados de forma incorreta, é necessário uma corrente maior para uma insensibilização eficiente, no entanto, não deve ser tão alta, pois causa prejuízos à qualidade da carne. O tempo de insensibilização por eletronarcose é em média, 15 milésimos de segundos, o que é suficiente para que seja realizada a sangria (Ricci \& Dalla Costa, 2015).

No método de exposição à atmosfera controlada é utilizado dióxido de carbono $\left(\mathrm{CO}_{2}\right)$ ou mistura de $\mathrm{CO}_{2}$ com outros gases. A concentração mínima de gases para insensibilização é de $70 \%$ para suínos e os animais devem sair do ambiente totalmente insensibilizado. Este método possui algumas vantagens em relação à insensibilização elétrica, como ausência de lesões e fraturas na carcaça dos animais e possibilidade de insensibilizar mais de um suíno por vez. Para verificar se a insensibilização foi adequada, o funcionário responsável por essa etapa deve observar parâmetros nos animais como enrijecimento dos membros, posição da cabeça, movimentação dos olhos quando tocados, paralisação temporária dos movimentos respiratórios e inconsciência. É 
fundamental esse monitoramento para que os suínos passem pela sangria corretamente insensibilizados (Ricci \& Dalla Costa, 2015).

A sangria é a técnica de abate dos animais e estes só deverão ser sangrados após a verificação de que estão completamente insensibilizados. Deve ser feita imediatamente após a o método de insensibilização dos animais, provocando um rápido e completo escoamento do sangue, antes que o suíno retorne à consciência (Barbosa Filho \& Silva, 2004). A sangria pode ser executada horizontalmente ou verticalmente, no máximo 30 segundos após a insensibilização, através da secção dos grandes vasos na entrada do peito, conforme Brasil (1995). De acordo com Ricci \& Dalla Costa (2015) a sangria deve ocorrer por pelo menos três minutos, de modo que seja retirado aproximadamente $50 \%$ do sangue, não sendo recomendada a movimentação com os animais neste momento.

Para obter resultados satisfatórios na qualidade final da carne é necessário um comprometimento com o bem-estar animal nestas etapas, seguindo as normas de produção e com isso evitando a produção de carnes de baixa qualidade, com ocorrência de carnes PSE (carne pálida, flácida e exsudava) e DFD (carne escura, firme e seca) (Ludtke et al., 2012).

\section{Considerações Finais}

De acordo com o que foi abordado, pode-se dizer que o manejo desde a granja até o abate é fundamental para reduzir boa parte do estresse e das lesões sofridas pelos animais, sobretudo nas etapas de transporte e no abatedouro, diminuindo consequentemente as condenações de carcaças e os prejuízos dos produtores e das indústrias. Para se ter uma melhor qualidade da carne, todas as pessoas envolvidas na cadeia de produção de suínos devem estar comprometidas em prezar pela sanidade e pelo bem-estar animal, evitando que os animais passem por sofrimentos desnecessários. O manejo pré-abate adequado também agrega valor ao produto final e satisfaz cada vez mais os consumidores.

\section{Referências Bibliográficas}

Barbosa Filho, J. A. D. \& Silva, I. J. O. (2004). Abate humanitário: ponto fundamental do bem-estar animal. Revista Nacional da Carne, $328,36-44$.

Beattie, V. E., Burrows, M. S., Moss, B. W. \& Weatherup, R. N. (2002). The effect of food deprivation prior to slaughter on performance, behaviour and meat quality. Meat Science, 62, 413-418.

Correa, J. A., Torrey, S., Devillers, N., Laforest, J. P., Gonyou, H. W. \& Faucitano, L. (2010). Effects of different moving devices at loading on stress response and meat quality in pigs. Journal of Animal Science, 88, 4086-4093.

Costa, L. N., Fiego, D. P., Dall'Olio, S., Davoli, R. \& Russo, V. (2002). Combined effects of pre-slaughter treatments and lairage time on carcass and meat quality in pigs of different halothane genotype. Meat Science, 61, 41-47.

Dalla Costa, O. A., Coldebella, A., Costa, M. J. R. P., Faucitano, L., Peloso, J. V., Ludke, J. V. \& Scheuermann, G. N. (2006). Período de descanso dos suínos no frigorífico e seu impacto na perda de peso corporal e em características do estômago. Ciência Rural, 36, 1582-1588.

Dalla Costa, O. A., Costa, M. J. R. P., Ludke, J. V., Coldebella, A., Kich, J. D., Peloso, J. V., Faucitano, L. \& Dalla Roza, D. (2008). Relation of fasting time during pre-slaughter management to weight loss, weight of stomach contents and incidence of gastric ulcer in pigs. Ciência Rural, 38, 199-205.

Dalla Costa, O. A., Ludke, J. V., Coldebella, A., Kich, J. D., Costa, M. J. R. P., Faucitano, L., Peloso, J. V. \& Dalla Roza, D. (2009). Efeito do manejo pré-abate sobre alguns parâmetros fisiológicos em fêmeas suínas pesadas. Ciência Rural, 39, 852-858.

Dalla Costa, O. A., Ludke, J. V., Costa, M. J. R. P., Faucitano, L., Peloso, J. V. \& Dalla Roza, D. (2007). Modelo de carroceria e seu impacto sobre o bem-estar e a qualidade da carne dos suínos. Ciência Rural, 37, 14181422 .

Dalla Costa, O. A., Ludke, J. V., Costa, M. J. R. P., Faucitano, L., Peloso, J. V. \& Dalla Roza, D. (2010). Efeito das condições pré-abate sobre a qualidade da carne de suínos pesados. Archivos de Zootecnia, 59, 391-402.

Esteves, A. S., Saraiva, C., Morgado, C., Fontes, M., Ribeiro, P., Soares, K. \& Saraiva, S. (2014). Avaliação do bem-estar no transporte e nos currais de descanso pela ocorrência de lesões em carcaças de suínos abatidos em matadouro. Brazilian Journal of Veterinary Research and Animal Science, 51, 333-339. 
FAPRI. (2015). Food and Agricultural Policy Research Institute. In: Database, W. A. O. (ed.) Food and Agricultural Policy Research Institute. Iowa State University and University of Missouri-Columbia Ames, IA, USA.

Faucitano, L. (2000). Efeitos do manuseio préabate sobre o bem-estar e sua influência sobre a qualidade de carne. Conferência virtual internacional sobre qualidade de carne suína. EMBRAPA, Concórdia.

FAWC. (2009). Farm animal welfare in Great Britain: Past, present and future. Farm Animal Welfare Council, England.

Garcia, A. \& McGlone, J. J. (2015). Loading and unloading finishing pigs: Effects of bedding types, ramp angle, and bedding moisture. Animals, 5, 13-26.

Gispert, M., Faucitano, L., Oliver, M. A., Guàrdia, M. D., Coll, C., Siggens, K., Harvey, K. \& Diestre, A. (2000). A survey of preslaughter conditions, halothane gene frequency, and carcass and meat quality in five Spanish pig commercial abattoirs. Meat Science, 55, 97-106.

Guàrdia, M. D., Estany, J., Balasch, S., Oliver, M. A., Gispert, M. \& Diestre, A. (2005). Risk assessment of DFD meat due to pre-slaughter conditions in pigs. Meat Science, 70, 709-716.

Israel, H. T., Omar, A. R., Conrado, L. P. A., Alfredo, S. B., Francisco, H. D. \& Gloria, H. V. (2010). Manejo pré-abate e qualidade de carne. Handling pre. REDVET. Revista electrónica de Veterinaria, 1695, 1-11.

Kephart, K. B., Harper, M. T. \& Raines, C. R. (2010). Observations of market pigs following transport to a packing plant. Journal of Animal Science, 88, 2199-2203.

Köhler, R. G. \& Freitas, R. J. S. (2005). Qualidade da carne suína após dois tempos de descanso no frigorífico. Archives of Veterinary Science, 10, 89-94.

Lewis, N. J. \& Berry, R. J. (2006). Effects of season on the behaviour of early-weaned piglets during and immediately following transport. Applied Animal Behaviour Science, 100, 182-192.

Ludtke, C. B., Dalla Costa, O. A., Roça, R. d. O., Silveira, E. T. F., Athayde, N. B., Araújo, A. P., Mello Júnior, A. \& Azambuja, N. C. (2012). Bem-estar animal no manejo pré-abate e a influência na qualidade da carne suína e nos parâmetros fisilógicos do estresse. Ciência Rural, 42, 532-537.

Machado, S. T., Santos, R. C., Caldara, F. R., Gonçalves, M. C., Jordan, R. A. \& dos Reis, J. G. (2014). Operação de transporte e tempo de descanso na incidência de carne PSE em suínos. Revista Brasileira de Engenharia Agrícola e Ambiental, 18, 1065-1071.

Miranda-de la Lama, G. C., Villarroel, M., Liste, G., Escós, J. \& María, G. A. (2010). Critical points in the pre-slaughter logistic chain of lambs in Spain that may compromise the animal's welfare. Small Ruminant Research, 90, 174-178.

Miranda-de la Lama, G. C., Villarroel, M. \& María, G. A. (2014). Livestock transport from the perspective of the pre-slaughter logistic chain: a review. Meat Science, 98, 9-20.

Molento, C. F. M. (2005). Bem-estar e produção animal: Aspectos econômicos - Revisão. Archives of Veterinary Science, 10, 1-11.

Murray, A. C. (2000). Reduzindo perdas da porteira da granja até o abatedouro-uma perspectiva canadense. Conferência Internacional Virtual sobre Qualidade de Carne Suína. EMBRAPA, Concórdia.

Nielsen, B. L., Dybkjær, L. \& Herskin, M. S. (2011). Road transport of farm animals: effects of journey duration on animal welfare. Animal, 5, 415-427.

Owen, B. L., Montgomery, J. L., Ramsey, C. B. \& Miller, M. F. (2000). Preslaughter resting and hot-fat trimming effects on the incidence of pale, soft and exudative (PSE) pork and ham processing characteristics. Meat Science, 54, 221-229.

Raj, M. (2000). Efeito dos métodos de atordoamento e de abate sobre a qualidade da carne de porco. 1 Conferência Internacional Virtual sobre Qualidade de Carne Suína. Concórdia.

Ricci, G. D. \& Dalla Costa, O. A. (2015). Humane slaughter of swine. Revista de Ciências Agroveterinárias, 14, 267-272.

Santiago, J. C., Caldara, F. R., Santos, V. M., Seno, L. O., Garcia, R. G. \& Almeida Paz, I. C. (2012). Incidência da carne PSE (pale, soft, exsudative) em suínos em razão do tempo de descanso pré-abate e sexo. Arquivo Brasileiro 
de Medicina Veterinaria e Zootecnia, 64, 1739-1746.

Santos, R. C., Reis, J. G. M., Machado, S. T., Jordan, R. A., Oliveira, R. V. \& Moura, G. B. (2013). Perdas econômicas decorrentes do transporte de suínos em Mato Grosso do Sul: Estudo de caso. Enciclopédia Biosfera, Centro Científico Conhecer, 9, 1682-1697.

Schwartzkopf-Genswein, K. S., Faucitano, L., Dadgar, S., Shand, P., González, L. A. \& Crowe, T. G. (2012). Road transport of cattle, swine and poultry in North America and its impact on animal welfare, carcass and meat quality: A review. Meat Science, 92, 227-243.

Silva, J. A. O., Simões, G. S., Rossa, A., Oba, A., Ida, E. I. \& Shimokomaki, M. (2011). Manejo pré-abate de transporte e banho sobre a incidência de mortalidade de frangos de corte. Semina: Ciências Agrárias, 32, 795-800.
Yu, J., Tang, S., Bao, E., Zhang, M., Hao, Q. \& Yue, Z. (2009). The effect of transportation on the expression of heat shock proteins and meat quality of $\mathrm{M}$. longissimus dorsi in pigs. Meat Science, 83, 474-478.

\section{Article History}

Received 29 August 2016

Accepted 14 September 2016

Available on line 11 October 2016

License information: This is an open-access article distributed under the terms of the Creative Commons Attribution License 4.0, which permits unrestricted use, distribution, and reproduction in any medium, provided the original work is properly cite 